\title{
Quantifying asbestos in lung tissue: what debate?
}

\author{
Benoit Nemery ${ }^{1}$, Valerie Nuyts $^{1}$ and Kristiaan Nackaerts ${ }^{2}$
}

Affiliations: ${ }^{1}$ Centre for Environment and Health, Dept of Public Health and Primary Care, KU Leuven, Leuven, Belgium. ${ }^{2}$ Division of Respiratory Diseases, University Hospitals Leuven, Leuven, Belgium.

Correspondence: Benoit Nemery, Centre for Environment and Health, Dept of Public Health and Primary Care, KU Leuven, Herestraat 59 (0\&N) 706), 3000 Leuven, Belgium. E-mail: Ben.Nemeryamed.kuleuven.be

@ERSpublications

The implications of the "chrysotile debate" reach far beyond scientific circles http://ow.ly/OUNj30bPSGU

Cite this article as: Nemery B, Nuyts V, Nackaerts K. Quantifying asbestos in lung tissue: what debate? Eur Respir J 2017; 49: 1700861 [https://doi.org/10.1183/13993003.00861-2017].

This issue of the European Respiratory Journal contains an article entitled "The asbestos fibre burden in human lungs: new insights into the chrysotile debate" by FEDER et al. [1]. Although respiratory physicians are very familiar with the devastating health effects of past asbestos exposure, many nonspecialist readers probably wonder what this "chrysotile debate" might be and how this article provides new insights into it. The debate involves the biopersistence and, hence, harmfulness of chrysotile as opposed to other types of asbestos. As is often the case with environmental issues, the implications of the debate are not just scientific.

Asbestos is a commercial (rather than a geological) term that refers to a group of naturally occurring fibrous silicates. Two types of asbestos can be distinguished based on mineralogical characteristics: serpentines (essentially chrysotile, known as "white asbestos") and amphiboles (including crocidolite, known as "blue asbestos"; amosite, known as "brown asbestos"; tremolite, which may contaminate chrysotile; and other minerals) [2]. Chrysotile has been the predominant type of asbestos used in industry, and it is still produced, exported and used in some countries, especially industrialising countries [3, 4]. In general, asbestos fibres have great chemical and heat resistance, and they were/are very cheap to mine and process. This is why asbestos has been used for numerous industrial applications: for fire protection and insulation (in buildings, power plants, ships, trains, ovens and domestic appliances), for reinforcing a wide variety of materials (most notably, cement to make asbestos-cement products, but also textiles, plaster, plastics, cardboard, paints, putties, glues, etc.), and for friction and filtration purposes, to name but the main uses. However, the use of asbestos has come at a considerable cost in terms of human health, mainly for workers whose jobs involved handling asbestos or asbestos-containing materials, but also for their families and people living close to facilities handling asbestos, as well as for future generations of workers and the general public who might come into contact with the legacy of the widespread usage of asbestos. These adverse health effects have led to the progressive phasing out and then complete banning of asbestos in most industrially developed countries. Nevertheless, this does not mean that asbestos is no longer a threat, because asbestos is still present in many places. Moreover, and importantly for the chrysotile debate, chrysotile asbestos has not been banned from use in many countries, especially emerging economies.

The most well-established diseases caused by the inhalation of asbestos fibres are asbestosis (a term that should only be used for pulmonary fibrosis caused by asbestos), nonmalignant pleural lesions (pleural

Received: April 252017 | Accepted: April 262017

Support statement: This work was support by Stichting Tegen Kanker. Funding information for this article has been deposited with the Crossref Funder Registry.

Conflict of interest: Disclosures can be found alongside this article at erj.ersjournals.com

Copyright OERS 2017 
plaques, pleural effusion and diffuse pleural fibrosis without or with round atelectasis), lung cancer and malignant mesothelioma (of the pleura or peritoneum) $[2,5]$. There is a consensus that the amphiboles have great potential to induce fibrosis and mesothelioma, and this has generally been attributed to the long biopersistence (decades) of amphibole fibres in the lung and their translocation to the pleura. Amphibole fibres give rise to the formation of asbestos bodies (AB), structures consisting of iron-rich protein-mucopolysaccharide material around a fibre, that are easily recognisable by light microscopy in lung biopsies or bronchoalveolar lavage (BAL) $[6,7]$. In contrast, chrysotile fibres are generally considered to be cleared rapidly from the lungs [8] and, hence, they are less prone to form asbestos bodies $[6,8]$. The lower biopersistence of chrysotile could explain why exposure to chrysotile appears to be less hazardous than exposure to amphiboles. However, the lower potential of chrysotile to cause mesothelioma does not mean that chrysotile is not carcinogenic, let alone safe to handle, as some chrysotile producers would like us to believe.

How does the article by FEDER et al. [1] provide insights into the chrysotile debate? The authors exploited a very large database, the German Mesothelioma Register, consisting of almost 24000 patients in whom the lung burden of asbestos fibres had been determined between 1987 and 2015. They evaluated the data from the 12 individuals in whom a "substantial" number of asbestos bodies (>500 AB.g ${ }^{-1}$ wet lung tissue) had been counted twice: first, during their lifetime, in surgically obtained lung tissue (10 patients) or in bronchoalveolar lavage (two patients), and then again at autopsy $\geqslant 4$ years later (median 8 years). All 12 patients died from an asbestos-related disease. One conclusion of the study is that the concentration of asbestos fibres in the lung tissue did not decrease with time; if anything, the concentration of $A B$ in lung tissue was higher at autopsy than at surgery, but this could be explained by fewer sampling errors at autopsy. Another conclusion of relevance for the chrysotile debate is that the fibres that were identified by electron microscopy coupled with energy dispersive X-ray analysis (EM-EDX) in six subjects were predominantly crocidolite in two patients and predominantly chrysotile in four patients. The latter observation seems to contradict the commonly accepted notion of a low biopersistence of chrysotile in the lung tissue. In their discussion, the authors do not dispute that inhaled chrysotile fibres are cleared rapidly from the lungs but they argue that such clearance has been shown to occur early after exposure [8] and they reasonably conclude that their observations confirm that those chrysotile fibres that have escaped the early clearance mechanisms persist for many years in the lung.

The scientific merit of this article is, first, that it presents a unique and original investigation in a relevant area of respiratory and occupational medicine. A further positive point is that the data came from a single laboratory that used standardised procedures throughout the study period, thus minimising the influence of variability in sample preparation and identification or counting of asbestos. However, an obvious but understandable weakness of the study is the very low number of subjects included: 12 patients in the main study with EM-EDX analyses performed in only half of them. These low numbers explain the wide interindividual variation in the results and they may lead to a question over the generalisability of the findings (in this respect, the use of percentages in the article is a little disingenuous). Nevertheless, the findings are what they are and it is not unreasonable to assume that similar results would probably be obtained in a study with more patients. Another, less critical limitation is that the study was conducted among patients with overt asbestos-related diseases and a high lung-fibre burden several years after the cessation of exposure. It is unlikely, given the invasive nature of the procedure needed to obtain such data, that we will ever know what happens in lungs with lower asbestos burdens.

The conclusion of FEDER et al. [1] that the asbestos burden remains stable with time (beyond the immediate post-exposure period) is, to some extent, supported by our retrospective study of asbestos bodies in BAL [9]. In that study, we also had a few subjects (10 out of 578 patients) for whom two counts were available. The median interval between the two samples was 2.4 years (range 44 days to 10 years), and the median difference between the second and first assessment was 0 (however, with a broad range of -28.3 to $+31.1 \mathrm{AB} \cdot \mathrm{mL}^{-1}$ ). Three subjects had zero values on both occasions and in the seven other subjects, the first values did not differ significantly from the second values (median 7.1 versus 6.7 $\left.\mathrm{AB} \cdot \mathrm{mL}^{-1}\right)$.

Finally, it should be realised that the phrase "chrysotile debate" is not neutral. Indeed, the asbestos industry has applied the tactics used by other "merchants of doubt" [10], most notoriously the tobacco industry and climate sceptics, to create or exaggerate, with help of "hired guns", uncertainty about adverse effects. The largely manufactured controversy is used to counter restrictive legislation and, in the case of asbestos, to justify the use of chrysotile. Unfortunately, we may fear that the scientific insights provided by the meritorious study of FEDER et al. [1] will not be sufficient to sway the economic interests of those who maintain that chrysotile can be used safely. That the "debate" about asbestos reaches far beyond scientific circles has been illustrated by the recent discovery that a spy allegedly working for the asbestos industry had infiltrated the main nongovernmental organisation campaigning for a worldwide ban of asbestos [11]. 


\section{References}

1 Feder I, Tischoff I, Theile A, et al. The asbestos fibre burden in human lungs: new insights into the chrysotile debate. Eur Respir J 2017; 49:1602534.

2 Newman Taylor A, Cullinan P, Blanc P, et al. Parkes' Occupational Lung Disorders. 4th Edn. Boca Raton, CRC Press, 2016.

3 Frank AL, Joshi TK. The global spread of asbestos. Ann Global Health 2014; 80: 257-262.

4 Takahashi K, Landrigan PJ. The global health dimensions of asbestos and asbestos-related diseases. Ann Global Health 2016; 82: 209-213.

5 Craighead JE, Abraham JL, Churg A, et al. The pathology of asbestos-associated diseases of the lungs and pleural cavities: diagnostic criteria and proposed grading schema. Report of the Pneumoconiosis Committee of the College of American Pathologists and the National Institute for Occupational Safety and Health. Arch Pathol Lab Med 1982; 106: 544-596.

6 Churg AM, Warnock ML. Asbestos and other ferruginous bodies: their formation and clinical significance. Am J Pathol 1981; 102: 447-456.

7 De Vuyst P, Karjalainen A, Dumortier P, et al. Guidelines for mineral fibre analyses in biological samples: report of the ERS Working Group. Eur Respir J 1998; 11: 1416-1426.

8 Churg A, Wright JL. Persistence of natural mineral fibers in human lungs: an overview. Environ Health Perspect 1994; 102: Suppl. 5, 229-233.

9 Nuyts V, Vanhooren H, Begyn S, et al. Asbestos bodies in bronchoalveolar lavage in the 21st century: a time trend analysis in a clinical population. Occup Environ Med 2017; 74: 59-65.

10 Oreskes N, Conway EM. Merchants of Doubt: How a Handful of Scientists Obscured the Truth on Issues from Tobacco Smoke to Global Warming. London, Bloomsbury Press, 2010.

11 Cobain I. Corporate Spy Infiltrated Anti-Asbestos Campaign, Court Told. https://www.theguardian.com/world/ 2016/dec/08/k2-corporate-spy-infiltrated-anti-asbestos-campaign-court-told Date last updated: December 8, 2016. 